\title{
Aplikasi Filter Multivariate Empirical Mode Decomposition (MEMD) Untuk Mereduksi Noise pada Data VLF-EM
}

\author{
Muhammad Shafran Shofyan, Anik Hilyah, dan Juan Pandu G.N.R \\ Jurusan Teknik Geofisika, Fakultas Teknik Sipil dan Perencanaan, Institut Teknologi Sepuluh \\ Nopember (ITS) \\ Jl. Arief Rahman Hakim, Surabaya 60111 Indonesia \\ e-mail: anik@geofisika.its.ac.id
}

\begin{abstract}
Abstrak-Alat VLF-EM menangkap gelombang elektromagnetik dari medium-medium disekitarnya. Sehingga, alat VLF-EM ini sangat sensitif terhadap benda-benda yang memiliki komponen listrik dan magnet yang besar. Bendabenda tersebut dapat dikatakan sebagai sumber noise. Selain itu, radiasi medan elektromagnetik akibat kilat dan petir juga merupakan sumber noise pada pengukuran VLF-EM. Noisenoise tersebut akan memengaruhi data dan mengakibatkan kesalahan interpretasi. Oleh sebab itu, perlu dilakukan penelitian yang berjudul "Aplikasi Filter Multivariate Empirical Mode Decomposition (MEMD) Untuk Mereduksi Noise Pada Data VLF-EM" untuk menghilangkan noise-noise yang ada sehingga hasil akan lebih mudah untuk diinterpretasi. Penggunaan filter MEMD ini dikarenakan filter ini baik digunakan untuk mengolah sinyal secara multivariate. Pada penelitian ini dilakukan perbandingan antara data yang difilter dengan filter moving average dengan data yang di-filter dengan filter MEMD. Dari hasil penelitian ini, diketahui bahwa filter MEMD dapat mereduksi noise-noise yang memiliki frekuensi yang tinggi, terlihat dari hasil penampang resistivitas yang dihasilkan dari proses inversi.
\end{abstract}

Kata Kunci-Moving Average, Multivariate Empirical Mode Decomposition (MEMD), Noise, VLF-EM

\section{PENDAHULUAN}

$\mathrm{P}$ ENGUKURAN VLF-EM dilakukan untuk mengetahui rekahan yang ada pada suatu daerah. Pada saat pengukuran dengan menggunakan metode VLF-EM ini terdapat beberapa parameter penting yang perlu diperhatikan. Parameter-parameter ini akan memengaruhi kualitas dari data pengukuran. Pengaruh atmosfer merupakan salah satu parameter pentingnya, dimana pengaruh atmosfer seperti radiasi akibat kilat dan badai magnetic merupakan sumber noise utama dalam pengukuran VLF-EM sehingga akan sangat memengaruhi data pengukuran dan akan mempersulit proses interpretasi [1].

Oleh sebab itu, untuk mereduksi noise pada data VLF-EM perlu dilakukannya filtering. Filter yang digunakan pada penelitian ini adalah filter Multivariate Empirical Mode Decomposition (MEMD). Filter ini digunakan karena filter MEMD baik digunakan untuk mengolah sinyal multivariate dimana data yang didapat pada alat VLF-EM merupakan data multivariate.

\section{II.TINJAUAN PUSTAKA}

\section{A. Metode Very Low Frequency Electromagnetic (VLF- $\mathrm{EM})$}

Metode VLF-EM memanfaatkan gelombang elektromagnetik (medan magnet dan medan listrik) yang berada dibumi. Medan elektromagnetik primer dari sebuah pemancar radio memiliki komponen medan listrik $E_{z}$ dan komponen medan magnetic horizontal $\mathrm{H}_{\mathrm{y}}$ yang tegak lurus terhadap arah perambatan sumbu $\mathrm{x}$, sehingga bila jarak sebuah anomali yang bersifat konduktif cukup jauh dengan antenna pemancar, maka komponen medan elektromagnetik primer $\mathrm{H}_{\mathrm{y}}$ dianggap sebagai gelombang yang berjalan secara horizontal dan akan menginduksi anomaly sehingga akan menimbulkan arus induksi. Nilai arus induksi ini berbanding lurus dengan nilai konduktivitas dari suatu batuan [2].

Arus induksi ini nantinya akan menghasilkan medan magnet sekunder dengan frekuensi yang sama namun dengan fase yang berbeda. Sedangkan, nilai medan magnetik vertical $\mathrm{H}_{\mathrm{z}}$ berguna untuk menentukan anomali.

Gelombang ini yang digunakan untuk mengetahui perbedaan konduktivitas bawah permukaan dengan memanfaatkan persamaan Maxwell.

$$
\begin{array}{ll}
\nabla x \boldsymbol{H}=(\sigma+i \omega \varepsilon) \boldsymbol{E} & \text { (Hukum Ampere) } \\
\nabla x \boldsymbol{E}=-\left(i \omega \mu_{0}\right) \boldsymbol{H} & \text { (Hukum Faraday) }
\end{array}
$$

\section{B. Filter Multivariate Empirical Mode Decompotition (MEMD)}

Multivariate Empirical Mode Decomposition (MEMD) adalah pengembangan dari proses EMD dan Ensemble EMD (EEMD) karena EMD dan EEMD masih menghasilkan modus campuran yang mengakibatkan noise residual tidak terbaca pada IMF-IMF yang ada. Selain itu, proses EMD dan EEMD hanya bisa menangani masalah univariat saja sedangkan masalah multivariate belum bisa diatasi. Sehingga inphase dan quadrature hanya bisa dilakukan pengolahan secara terpisah, padahal interpretasi dan analisis yang dilakukan pada kedua sinyal tersebut harus dilakukan bersamaan untuk mengetahui informasi timbal baliknya. Oleh sebab itu, untuk menyelesaikan masalah multivariate diperlukan multivariate EMD (MEMD) dimana MEMD berfungsi untuk meningkatkan IMF-IMF yang ada sehingga 
IMF multivariate yang serupa namun memiliki frekuensi yang berbeda dapat lebih jelas terlihat.

Multivariate Empiracal Mode Decomposition (MEMD) merupakan perluasan dari EMD dimana EMD menentukan $\mathrm{K} \mathrm{IMF} \mathrm{c}_{1}(\mathrm{t}), \mathrm{c}_{2}(\mathrm{t}), \ldots, \mathrm{c}_{\mathrm{k}}(\mathrm{t})$ dan sinyal residu $\mathrm{r}(\mathrm{t})$ dari sebuah sinyal.

(3)

$$
\mathrm{x}(\mathrm{t})=\sum_{\mathrm{i}=1}^{\mathrm{K}} \mathrm{c}_{\mathrm{i}}(\mathrm{t})+\mathrm{r}(\mathrm{t})
$$

MEMD pertama kali diusulkan oleh Rehman dan Mandic[3]. untuk memproses sinyal multivariate yang memiliki jumlah channel yang sembarang. Penelitiannya menganggap $\mathrm{V}(\mathrm{s})=\left\{\mathrm{v}_{1}(\mathrm{~s}), \mathrm{v}_{2}(\mathrm{~s}), \ldots, \mathrm{v}_{\mathrm{n}}(\mathrm{s})\right\}$ adalah sekumpulan $\mathrm{n}$ data spasial sebagai fungsi ruang (s) dan $\mathrm{X} \theta=\left\{\mathrm{x}_{1}{ }^{\mathrm{k}}, \mathrm{x}_{2}{ }^{\mathrm{k}}, \ldots\right.$, $\left.\mathrm{x}_{\mathrm{n}}{ }^{\mathrm{k}}\right\}$ menunjukkan arah vector sepanjang arah yang diberikan oleh sudut dalam satu set arah. Kemudian, dari IMF kemudian set data spasial diperoleh sari penggunaan algoritma 1 yaitu:

1) Bangkitkan sekumpulan vektor arah yang sesuai, $X$.

2) Hitunglah sebuah proyeksi, $\mathrm{p}^{\theta \mathrm{k}}(\mathrm{s})$, dari sekumpulan data spasial $\mathrm{V}(\mathrm{s})$ sepanjang vector arah $\mathrm{X}^{\theta \mathrm{k}}$, untuk semua nilai $\mathrm{k}$.

3) Temukan sesaat spasial $\mathrm{s}_{\mathrm{i}}{ }^{\mathrm{k}}$ yang sesuai dengan maxima proyeksi untuk semua nilai $\mathrm{k}$.

4) Interpolasikan $\mathrm{s}_{\mathrm{i}}{ }^{\mathrm{ek}}$ dan $\mathrm{V}\left(\mathrm{s}_{\mathrm{i}}{ }^{\theta \mathrm{k}}\right)$ untuk memperoleh kurva multivariate envelope $\mathrm{e}^{\theta \mathrm{k}}(\mathrm{s})$ untuk semua nilai $\mathrm{k}$.

5) Rerata $\mathrm{M}(\mathrm{s})$ dari kurva envelope dihitung dengan $\mathrm{M}(\mathrm{s})=\frac{1}{\mathrm{~K}} \sum_{\mathrm{k}=1}^{\mathrm{K}} \mathrm{e}^{\theta \mathrm{k}}(\mathrm{s})$.

6) Ekstrak "detail" $\mathrm{D}(\mathrm{s})$ menggunakan $\mathrm{D}(\mathrm{s})=\mathrm{V}(\mathrm{s})-\mathrm{M}(\mathrm{s})$. Jika "detail" $\mathrm{D}(\mathrm{s})$ memenuhi kriteria penghentian IMF Multivariate, terapkan prosedur di atas untuk V(s)-D(s), jika tidak, terapkan ke $\mathrm{D}(\mathrm{s})$.

\section{METODOLOGI PENELITIAN}

Metodologi penelitian dari penelitian ini adalah dengan membandingkan hasil dari pengolahan data inphase dan quadrature yang di-filter dengan filter moving average kemudian dibandingkan dengan hasil pem-filter dengan MEMD. Berikut ini adalah diagram alir yang digunakan.

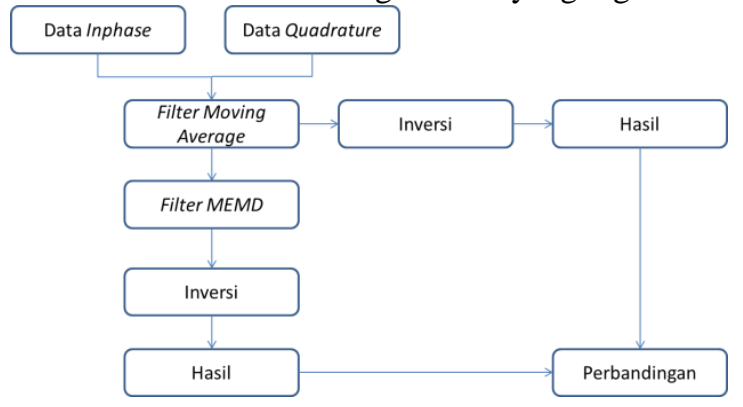

Gambar 1. Diagram Alir Metode Penelitian

\section{HASIL DAN PEMBAHASAN}

Filter moving average merupakan salah satu filter yang digunakan untuk mengoreksi nilai sinyal yang terlalu tinggi dan terlalu rendah dengan cara merata-ratakan jumlah data yang ingin di-filter, sehingga akan dihasilkan sinyal yang lebih smooth dan mempunyai kemenerusan. Pada penelitian ini, filter moving average digunakan pada setiap 3 data, jadi ketiga data tersebut akan dijumlahkan kemudian hasilnya akan dibagi 3. Berikut ini hasil filter moving average pada data inphase dan quadrature VLF-EM.
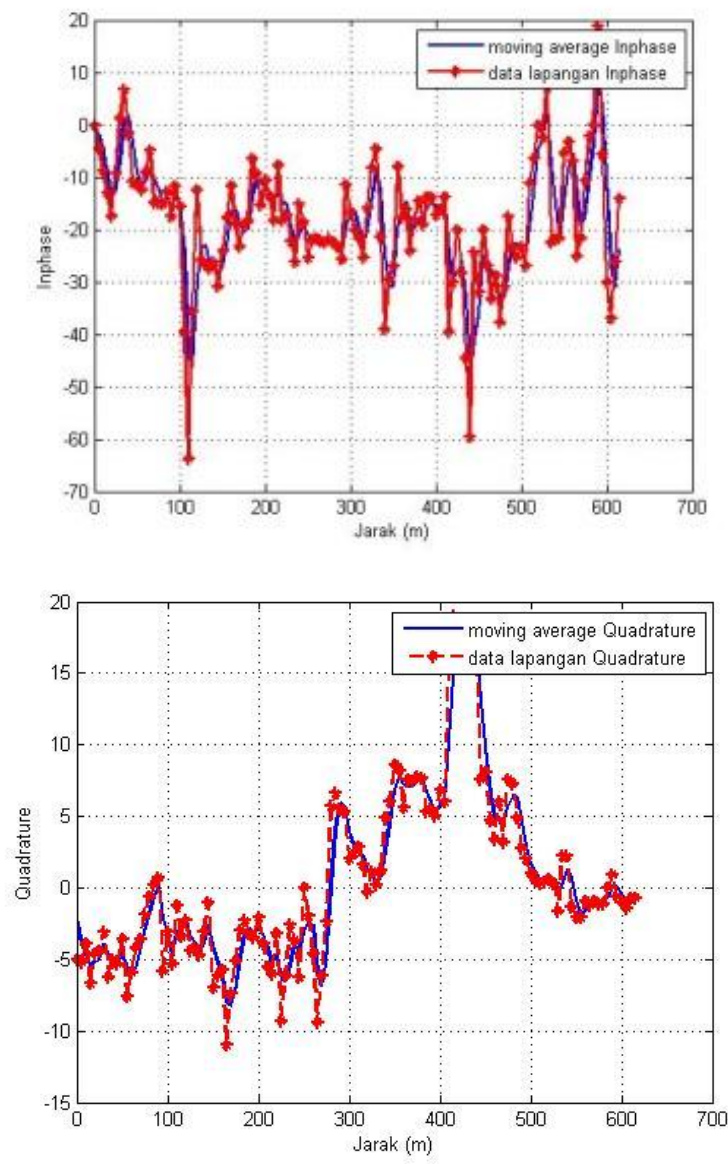

Gambar 2 Hasil Filter Moving average. inphase (atas), Ouadrature (bawah)

Dari hasil filter moving average kemudian dilakukan inversi untuk mendapatkan model resistivitasnya. Hasilnya ditunjukkan pada gambar 3 dibawah.

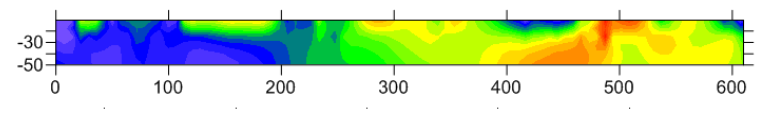

Gambar 3. Penampang resistivitas dari hasil filter moving average

Sedangkan penggunaan filter MEMD adalah dengan memilih IMF-IMF yang dihasilkan dari filter tersebut. Pemilihan ini bertujuan untuk menghapus frekuensi yang tinggi dan residual. Berdasarkan gambar 4 dibawah ini, IMF yang dipilih adalah IMF 3,4, dan 5 karena tidak mengandung frekuensi yang tinggi dan bukan residual. 

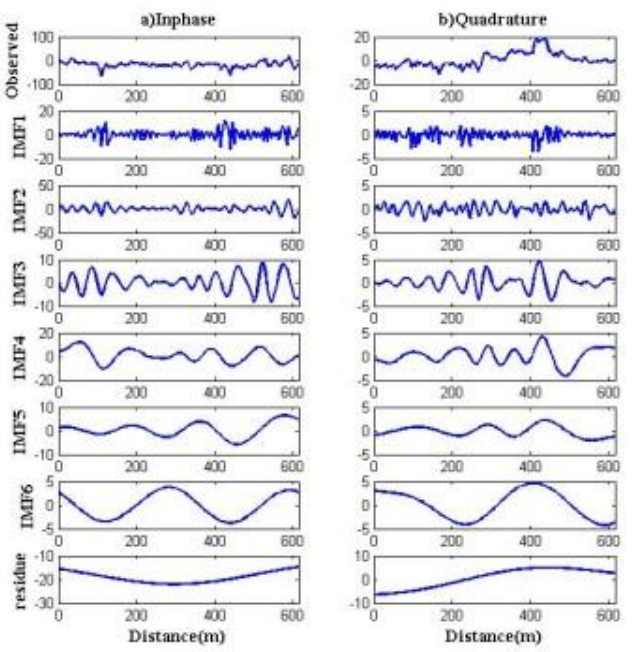

Gambar 4. IMF-IMF yang dihasilkan filter MEMD

IMF 3, 4, dan 5 tersebut akan dikalkulasikan sehingga akan didapatkan sinyal baru yang ditunjukkan pada gambar 4 dibawah ini.

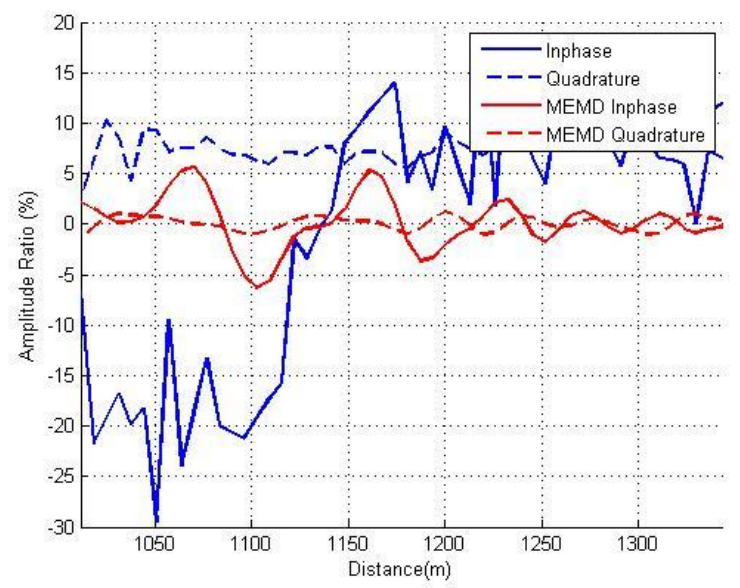

Gambar 5. Sinyal hasil filter MEMD

Dari hasil tersebut dilakukan proses inversi dan didapatkan model seperti berikut.

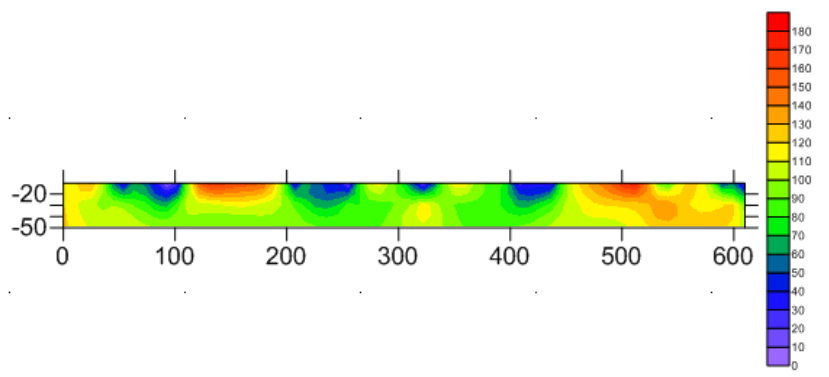

Gambar 6. Penampang resistivitas dari hasil filter MEMD

Berdasarkan perbandingan gambar 2 dan gambar 5, nilai inphase dan quadrature pada gambar 5 sudah tidak mengandung frekuensi-frekuensi yang tinggi dibandingkan dengan gambar 2, ini berdampak terhadap model resistivitas yang ditunjukkan pada gambar 3 dan 6, dimana terlihat bahwa hasil persebaran nilai resistivitas pada gambar 6 lebih menyebar dibandingkan dengan gambar 3 hal ini dipengaruhi dari nilai RMS errornya dimana gambar 3 memiliki RMS error sebesar 2.832 sedangkan gambar 6 memiliki RMS error sebesar 1.390. Selain itu, gambar 6 juga terlihat lebih mudah untuk dilakukan interpretasi posisi rekahan dimana rekahan tersebut ditunjukkan dengan nilai resistivitas 0-80 ohm meter (warna biru).

\section{KESIMPULAN}

Kesimpulan yang didapat dari penelitian ini antara lain.

1) Filter MEMD efektif untuk mereduksi noise yang ada pada data VLF-EM terlihat dari sinyal yang dihasilkan filter ini dimana frekuensi-frekuensi yang tinggi sudah tidak ada.

2) Model penampang resistivitas yang dihasilkan dari inversi data yang sudah di-filter MEMD memiliki RMS error yang lebih kecil dibanding data yang di-filter moving average yaitu 1.390 berbanding 2.832 .

\section{DAFTAR PUSTAKA}

[1] A. R. Parulian, Metode Elektromagnetik Very Love Frequency (VLF) untuk Pendugaan Struktur Bawah Permukaan Lapangan Merah Universitas Padjajaran Bandung, 2007.

[2] Y. Feriandi, Aplikasi Noise Assisted Multivariate Empirical Mode Decomposition pad Metode Very Low Frequency Electromagnetic untuk Analisa Tanggul Lumpur Sidoarjo. Thesis, Surabaya: Institut Teknologi Sepuluh Nopember, 2014.

[3]. N. Rehman and D. P. Mandic, "Multivariate empirical mode decomposition" Proc. R. Soc. Lond. Math. Phys. Eng. Sci., p. rspa20090502, Dec. 2009. 